\title{
Large endolymphatic sac anomaly
}

\author{
Karl Muchantef • Ajay Malhotra
}

Received: 26 November 2009 /Revised: 4 February 2010/Accepted: 15 February 2010/Published online: 23 March 2010

(C) Springer-Verlag 2010

A 31-month-old girl presented with sensorineural hearing loss. Brain MRI demonstrated enlargement of the endolymphatic sacs bilaterally on T2-W images (Fig. 1) and reformatted image on the left side (Fig. 2, white arrow). The remaining inner ear structures were unremarkable.

The endolymphatic sac sits at the posterior aspect of the petrous bone. The endolymphatic duct leads through the bony vestibular aqueduct from the utricle and saccule to the endolymphatic sac. The normal endolymphatic sac is barely visualized on high-resolution T2-W MRI. When enlarged, the finding is termed the large endolymphatic sac anomaly. Because CT better demonstrates bony anatomy,

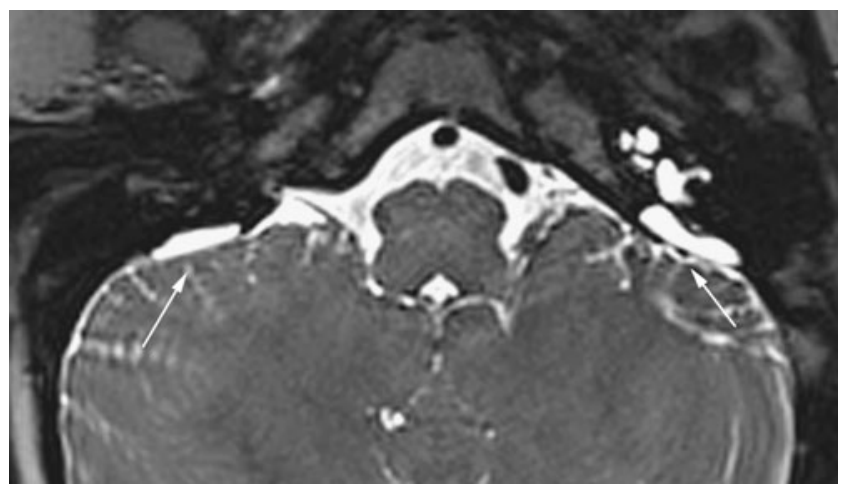

Fig. 1 T2-W MR image of the brain

K. Muchantef $\cdot$ A. Malhotra

Department of Radiology, Yale University School of Medicine, New Haven, CT, USA

\section{A. Malhotra $(\square)$}

Department of Radiology, Division of Neuroradiology,

University of Rochester Medical Center,

601 Elmwood Ave., P.O. Box 648, Rochester, NY 14642, USA

e-mail: ajayradiology@yahoo.com

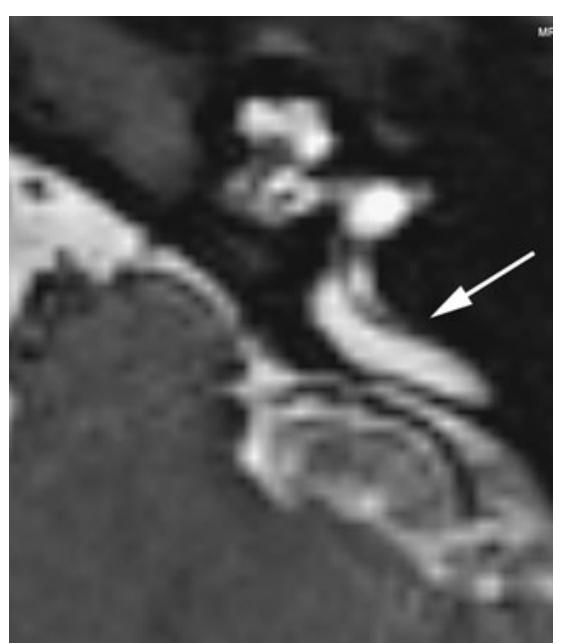

Fig. 2 Reformatted image, left side

the CT correlate is termed the large vestibular aqueduct syndrome. The vestibular aqueduct is considered enlarged when its diameter exceeds $1.5 \mathrm{~mm}$ at its midpoint. Cochlear dysplasia is a frequent association $[1,2]$. Children with this anomaly are usually born with normal or mildly impaired hearing, which deteriorates in childhood. Vertigo is a frequent complaint, though typically with a later onset. Treatment options include hearing aids and cochlear implantation.

\section{References}

1. Davidson HC, Harnsberger RH, Lemmerling MM et al (1999) MR evaluation of vestibulocochlear anomalies associated with large endolymphatic duct and sac. AJNR 20:1435-1441

2. Sennaroglu L, Saatci I (2002) A new classification for cochleovestibular malformations. Laryngoscope 112:2230-2241 